\title{
Origin, Development and Significance of L-forms in Bacterial Cultures
}

\author{
BY EMMY KLIENEBERGER-NOBEL \\ Lister Institute, London
}

SUMMARY: Several Gram-negative bacteria produce pleuropneumonia-like (L-) forms, some under ordinary cultural conditions, others only when exposed to abnormal ones. The formation of these bodies starts with the production of small nuclear elements surrounded with a thin cytoplasmic layer; these elements fuse with neighbouring elements and the $\mathbf{L}$-body is complete. Whereas some $\mathbf{L}$-strains reproduce themselves indefinitely, others revert to the bacterial form. Thus the bacterial and the $\mathbf{L}$-forms are now regarded as two different generations of the same organism and my symbiosis theory is abandoned.

Symbiosis was my explanation of the association between pleuro-pneumonialike organisms that breed true (L-forms) and Streptobacillus moniliformis (Klieneberger, 1935, 1942). In contrast, Dienes and others believe that the $\mathrm{L}$-form is either a variant or a phase in the life cycle of the Streptobacillus. Dienes's view $(1947,1948)$ that the L-forms arise from a simple swelling of the bacterium, that the large $\mathrm{L}$-forms are a reproductive phase and the small L-forms are bacteria-like is too simple; my opinion is, and always has been, that the bacterial and the L-forms differ fundamentally in cytology, colony form, metabolism (Partridge \& Klieneberger, 1941), and in pathogenicity. A typical young bacterium (which $\mathbf{I}$ designate an $\mathbf{A}$-form) has a wall of considerable thickness (see Fig. 1, Knaysi \& Baker, 1947) which gives rigidity to the cell. Inside the wall is a cytoplasmic layer, which becomes septate during division, enclosing the transversely arranged chromatinic structures called ' chromosomes' by Robinow (1944, 1945). At division a ring-like band forms on the inner side of the cell-wall and gradually cuts the cell in two but without obvious constriction of the outer part of the cell-wall. In contrast, the L-forms have only a thin cell boundary which may be no more than a fine layer of condensed cytoplasm; the cells are plastic and because they can assume any shape $I$ have described them as amorphous. They divide by segmentation into two or more parts (see Figs. 8 and 9, Smith, Hillier \& Mudd, 1948), the size and shape of these elements being determined by the physical conditions of the environment (Klieneberger \& Smiles, 1942). Chromatinic material may be present in big clumps or in particles too small for the resolving power of the light microscope; it may assume different shapes, including filaments (mycelium- or network-like), but it never shows the characteristic bacillary arrangement.

With these differences in mind it was clear that the origin and development of the A- and L-forms needed to be studied by the newer cytological methods developed by Robinow and by Boivin. This has been done with certain Gramnegative bacteria, some of which produce L-forms under ordinary cultural conditions, others only in special conditions that are often adverse to the growth of the organism. 


\section{Methods}

Young liquid cultures were inoculated on the solid medium and small squares of the agar cut out; these were placed inoculated side downwards on sterile coverslips, and incubated in a moist chamber. After incubation the agar square was removed and the wet coverslip film fixed in osmic acid vapour. Fixed preparations either without further treatment, or after treatment with warm $\mathrm{N}-\mathrm{HCl}$, or with a solution of ribonuclease, were stained with a weak Giemsa solution. Occasionally Bouin's fixative was applied through the agar; this was followed by tannic acid as a mordant and by dilute crystal violet to stain. (For further details of the methods applied see Klieneberger-Nobel, 1945; Robinow, 1944, 1945; Boivin, 1948; Boivin, Tulasne, Vendrely \& Minck, $1947 d$; Tulasne \& Vendrely, 1944).

\section{OBSERVATIONS}

\section{Formation of $\mathbf{L}$-growth under ordinary conditions of culture}

Fusiformis necrophorus (Bacteroides funduliformis). Strain 132, isolated by Dienes, was subcultured once a week for two years in Brewer's medium enriched with horse serum. The inoculum was large ( 3 or 4 drops) and was incubated at $36^{\circ}$ for only $7 \mathrm{hr}$; ; between subcultures, cultures were kept in the cold. Before each experiment the strain was subcultured three times a day on two successive days, when it consisted entirely of A-forms. When inoculated on to plates of 'special medium' (boiled blood agar made from ox-heart infusion peptone broth enriched with horse serum) these bacilli multiplied without lag phase and after $2-3 \mathrm{hr}$. anaerobic incubation the chromatinic structures ('chromosomes') were arranged more or less transversely in the cells (Pl. 1, fig. 1). With longer incubation these structures divided into smaller ones and many appeared as granules. The cytoplasm now stained more delicately than before and seemed to be poor in ribonucleic acid, for very little treatment was needed to show its chromatinic structures (Pl. 1, fig. 2); cellular outlines could hardly be demonstrated at this stage (3-4 hr.). A little later single nuclear granules and rows of granules embedded in delicately staining cytoplasm were seen almost exclusively; each granule, with its faint surrounding cytoplasm, seemed to represent one small unit (the 'primary cell unit') which tended to coalesce with neighbouring units (Pl. 1, figs. $3 a$ and $3 b$ ) after 4-5 $\mathrm{hr}$. incubation. In further development the nuclear granules grew into fine filaments (Pl. 1, figs. $3 a$ and $3 b$ ) which fused on contact with similar filaments or other nuclear granules (Pl. 1, fig. 6) to form a chromatinic network (Pl. 1, figs. 7-9). The nuclear matter might now contract towards the centre and leave free a uniform, lightly stained, cytoplasmic edge to form a large disklike body (PI. 1, fig. 10), which, because of its shape, size and structure, must be regarded as an L-body. Neighbouring primary cell units fused in twos, threes, or more up to fairly big complexes to produce a large L-body. Pl. 1, figs. 4 and 5 show fields in which only a few units have joined together. Two primary cell units belonging to different chains of primary cell units might 
join to form a small body of the two united elements with a filamentous appendage on either side; this formation resembled a bacillus with a bulbous swelling. The size and shape of the L-bodies largely depended on the number and arrangement of the primary cell units which joined together and explains the bizarre shapes the L-body often assumes. The young bodies, small or large, were sometimes extremely thin in substance but they soon built up their chromatinic and cytoplasmic material. The arrangement of the chromatinic material in the fully developed elements was not constant; sometimes it appeared as a chromatinic network, as finely dispersed granules, and sometimes it had a coarse appearance. With further incubation the $\mathbf{L}$-elements often increased in size and divided, by segmentation and constriction, into two or more parts at the same time.

In liquid and semi-solid media subdivision appeared to be more frequent and the single bodies were smaller than the giant flat bodies produced on the surface of solid media. After 5-7 hr. incubation almost all the growth of strain 132 often developed into L-forms (Pl. 2, fig. 11). Later the bodies showed condensation of the chromatinic material and the formation of finger-like protuberances into which the concentrated, darkly staining, filamentous nuclear material migrated. These protuberances broke away and appeared as young, well-defined and wellstained bacilli containing one or more conspicuous nuclear structures or 'chromosomes' (Pl. 2, fig. 12). After two days' incubation the culture was almost completely transformed into the A-form.

However, L-growth may remain stable, producing no A-forms. I have isolated from strain 132 two pure L-lines which were kept for a year and underwent 100 passages without reverting (Klieneberger-Nobel, 1947). Therefore we must conclude that while the L-form ordinarily produces the A-form it may--under conditions not yet defined-persist in the L-form for an indefinite time. On the other hand, the L-form is produced by the A-form at a special stage of its development by the union of small elements, called the primary cell units.

Streptobacillus moniliformis. This species has been studied extensively in the past and $I$ have isolated the $L$-form (then called $L_{1}$ ) in pure culture from several strains from different sources; one strain has undergone 650 passages in the course of 15 years and bred true to the L-type. The strain used for the present work, mouse 2, was kept in the laboratory for several years and for the last two years was maintained by the methods used for F. necrophorus, which caused it to grow almost entirely in the A-form; scanty L-growth was found only on the second day of incubation. On the first day growth was mainly composed of small, slender bacilli; however, at the edges of stained coverglass microcultures, groups of disintegrating bacilli could be found occasionally. Later fine nuclear structures appeared in similar places and their configurations suggested that they might be on the point of joining together. Later still groups of L-bodies were found at the edges of the preparations but a substantial amount of L-growth was never detected. Thus by regular transfers for two years, a culture which originally produced L-forms in abundance was so changed that in the first $\mathbf{2 4} \mathrm{hr}$. it produced only $\mathbf{A}$-forms and a few L-forms only during the second 
day. S. moniliformis is the smallest of these organisms studied here; consequently the transformation from the $\mathrm{A}$ - to the $\mathrm{L}$-form was more difficult to follow than in any of the other organisms. But I have no doubt that the transformation is basically the same as in F. necrophorus.

Bacterium coli. Strain 204 was obtained from Dr F. Kaufmann; its pleomorphism was noticed at first examination. After a few hours' growth on trypsin digest agar its bacillary forms disintegrated into very small elements which soon combined with each other (Pl. 2, fig. 13 and Pl. 4, fig. 37), and a little later the culture consisted almost exclusively of L-bodies (Pl. 2, figs. 13 and 14). After a period of L-growth the bodies reproduced the A-form; at this stage the nuclear material was very dense, stained darkly (Pl. 4, fig. 35) and had divided into chromosome-like filaments. In Pl. 4, fig. 35, the angular body below the large body seems to have been breaking up into bacillary forms; it is surrounded by a number of bacilli, apparently newly formed, having the darkly stained nuclear structure typical of young bacilli. Strain 204 was more penicillin-resistant than any other strain of the Bact. coli and salmonella groups tested; it grew without inhibition on nutrient agar containing 800 units penicillin/ml. All L-strains, as well as pleuropneumonia-like organisms, were found to be penicillin resistant. Morphologically strain 204 was the same on penicillin and penicillin-free media.

\section{Formation of $L$-growth under the infuence of various stimuli}

Change in temperature. A motile and well-flagellated strain of a Proteus sp. was studied. A needleful of dried culture was placed in the centre of a welldried plate and the organisms were allowed to grow at room temperature until a fairly large swarming edge had been produced; the plates were then kept in the cold room $\left(0 \cdot 5^{\circ}\right)$ for three days (see Ørskov, 1947). Plates were then incubated at $36^{\circ}$ for several hours and impression preparations were taken from the swarming edge every quarter- or half-hour. When taken from the cold the swarming edge showed a number of normal bacteria; others were transparent and contained a row of small chromatinic granules; free granules were also found between disintegrating bacterial filaments. It is supposed that the granules, together with a cytoplasmic envelope not always demonstrable by the methods employed, represent the primary cell units because after a short incubation they form delicate ramifications. It seems that by means of these ramifications neighbouring granules join to form larger mycelium-like chromatinic formations (Pl. 3, fig. 26). These chromatinic networks and the surrounding cytoplasm build up and take stains more easily so that fully developed L-bodies were usually detected after $1 \frac{1}{2}-2 \mathrm{hr}$. incubation (Pl. 3, fig. 27). The number of L-bodies produced by this method varied; 'spparently it depended on the stage in which the bacteria at the swarming edge were caught when transferred to the cold.

To prove this, undried plates were evenly inoculated with 1-2 drops of a young broth culture, incubated for 1, 2, 3, 4 or more hours and placed in the cold for three days. They were then reincubated and impression preparations taken during incubation. L-forms did not develop on plates given only $1 \mathrm{hr}$. 
of preliminary incubation, a few appeared in the 2-hr. plate, and the largest number were produced on the plate given a preliminary incubation of $\mathbf{3} \mathbf{h r}$. With longer incubation the number of L-forms decreased. The production of L-forms and the rapidity of their appearance was stimulated by very rich media; thus meat infusion peptone agar was superior to trypsin digest agar. When the L-forms were once established they multiplied more slowly than the A-forms, so that they were soon outnumbered. After 5-6 hr. the L-bodies underwent a change; the nuclear material condensed and the body formed finger-like processes into which the nuclear material migrated. The protuberances broke away and the bodies produced bacillary elements in much the same way as the L-bodies of $F$. necrophorus. After $12 \mathrm{hr}$. incubation L-forms were no longer detected.

Effect of sodium chloride. It has been known for a long time that 'large bodies' develop under the influence of salts. A strain of Pasteurella pestis, N.C.T.C. 144, was studied on various media with and without added $\mathrm{NaCl}$. During the first 5-6 hr. the organisms developed similarly on all the media. Media were usually inoculated at night with a young broth-culture, kept at room temperature until morning and then transferred to the incubator. After a few hours' incubation on $\mathrm{NaCl}(3 \%)$ agar a change occurred; the cells stained less deeply and their nuclear structure showed up on staining without previous treatment. Sometimes the cytoplasm was unstainable and the outline of the cells was lost; Pl. 2, fig. 16, shows a chain of normal cells flanked on either side by naked chromatinic structures. Many tortuous filaments showing numerous loops and bends might be found at the same time (Pl. 2, figs. 15, 17 and 18). Soon afterwards the cytoplasm of these loops and bends seemed to coalesce, the enclosed nuclear structures or granules formed fine ramifications by which they joined together and produced round and oval L-bodies (Pl. 2, figs. 15 and 17). Sometimes parallel bacterial filaments joined lengthwise, probably by combination of opposite primary cell units; a much wider filament was thus produced, with chromatinic matter in the network formation or condensation peculiar to L-growth (Pl. 2, fig. 19). By the union of a large number of primary cell units composite bodies of very peculiar appearance were produced (PI. 2, fig. 20).

Effect of lithium chloride. The action of lithium chloride on Gram-negative organisms has often been studied and most workers agree that the large bodies developing under its influence produce normal bacteria when transferred to media not containing lithium. Yet how bacteria form the large bodies has not been examined in great detail. Accordingly Bacterium coli-mutabile, N.C.T.C. 2495 was grown in nutrient agar containing lithium chloride in concentrations of 0.05 and $0.1 \%$. The lithium salt produced a conspicuous effect, particularly at the higher concentration. During the first few hours the nuclear structures of the bacilli were arranged in the 'chromosome' pattern and cell divisions took place. Later the cells had swollen slightly and the cell outline was not clearly defined; the cytoplasm was very thin and the nuclear content had been transformed into small structures or granules which filled the interior of the cells. Subsequently the cells broke up into primary cell units (Pl. 3, fig. 21). 
Disintegration was not always complete, for some of the units stayed together in the arrangement they occupied in the mother cell. The free chromatinic granules produced fine ramifications by which neighbouring units combined (Pl. 3, fig. 24) and the nuclear network increased and acquired a greater affinity for the stain; the cytoplasm also became visible (Pl. 3, fig. 22. As the culture aged, round and oval bodies differentiated out of the complexes of young L-matter; these bodies were flat disks on the surface of the solid medium. With aging, their dispersed nuclear matter condensed, leaving free a delicately staining cytoplasmic edge. At this stage (Pl. 3, fig. 23) the bodies sometimes showed a delicate outline but a real cell-wall was never seen. In the low concentrations of lithium used the L-bodies invariably produced the A-forms without transfer to new medium; after about $12 \mathrm{hr}$. the large bodies had divided up into smaller ones (Pl. 3, fig. 25) containing condensed nuclear matter; in some, finger-like protuberances into which nuclear matter had migrated could be seen. The protuberances became detached, their nuclear material divided into 'chromosomes' and the new bacteria were born.

Effect of penicillin. Penicillin often produces aberrant forms in bacteria (Gardner, 1940; Boivin et al. 1947; Braun \& Yalim, 1948). Four organisms, Bact. coli-mutabile, N.C.T.C. 2495; a Proteus sp., and Salmonella paratyphi-B 801 and 802, were examined and behaved alike; the development of one, $S$. paratyphi-B 802 will be described. Penicillin concentrations were chosen so that noticeable inhibition was avoided; $\mathbf{3}, \mathbf{7 \cdot 5}$, and 15 units $/ \mathrm{ml}$. were used for the paratyphoid strains and up to $200 \mathrm{units} / \mathrm{ml}$. for the more resistant organisms. At first the bacilli developed in the usual way and revealed the ordinary set of 'chromosomes'; after 4--6 hr. incubation they stained less well and consisted of long, slender, and often involved filaments; cultures on penicillin-free media consisted of rods. The nuclear material broke up and became less distinct and the cells disintegrated into granular material (Pl. 4, fig. 28). Often transparent bacterial filaments filled with a row of granules were seen and the granules were gradually set free. I believe that these granules represent the primary cell units which, by union with their own kind, produce the L-forms. After about $5 \mathrm{hr}$. incubation the small units were numerous (Pl. 4, fig. 31). One half to one hour later these granules developed ramifications which seemed to fuse with their neighbours; at the same time they increased in size and stainability (Pl. 4, fig. 30). Occasionally tortuous filamentous masses were found at the same time (Pl. 4, figs. 29 and 32). The primary cell-units developing in these involved filaments are presumably closely packed and in joining up, transform the whole clump of filaments into one large L-body; the various shapes of the resulting L-bodies are seen in Pl. 4, figs. $29 a, b, c$ and 32; other aspects of the fusion are shown in Pl. 4, figs. 34, 37 and 39. The irregular outlines of newly formed bodies (Pl. 4, figs. 39) can be understood only when it is realized that they have been produced by the combination of many small units. The period of fusion is followed by a period of building of nuclear and cytoplasmic substance, so that many well-coloured bodies, both large and small, are found between the bacterial filaments (Pl. 4, fig. 33). This is followed by a period of multiplication of the $\mathbf{L}$-bodies. 
After $18 \mathrm{hr}$. many L-bodies have produced bacteria (Pl. 4, fig. 38); the bacteria are recognized as young organisms by their well-stained and typically arranged 'chromosomes' (Pl. 4, fig. 36). In the left-hand corner of Pl. 4, fig. 36, a large L-body shows the deeply stained chromatinic material which seems to have broken up into short filaments which may represent the 'chromosomes' of the developing bacteria.

\section{DISCUSSION}

Dienes believes that the L-form represents a reproductive phase of bacteria. Tatum \& Lederberg's work (1947) is suggestive of the existence of a sexual phase in bacteria. To prove that the L-cycle is connected with such a phase it would be necessary to show that the $\mathrm{L}$-form is the product of a union of two bacterial elements, and that bacteria can be produced from the L-form. The only recently recorded evidence of union of bacterial elements is a single observation by Smith (1944) with a strain of Fusiformis necrophorus. Several workers (Dienes, 1943, 1948a; Dienes \& Smith, 1944; Smith, Mudd \& Hillier 1948) have shown that bacteria may arise from L-forms and these observations have been confirmed by the work reported in this paper.

The first stage in the development of the $\mathbf{L}$-form is the formation of very small cells (primary cell units) consisting of a chromatinic granule and a thin surrounding cytoplasm, poor in ribonucleic acid. These units fuse in a characteristic way: first the cytoplasm coalesces and then the nuclear granules produce ramifications which combine with neighbouring chromatinic structures. This union might be regarded as sexual, but it can involve any number of units from two upwards. Union is followed by an increase in both nuclear and cytoplasmic material and the L-body is then formed. Reproduction also is characteristic of the $\mathbf{L}$-body and differs from that of the A-form; there is segmentation and constriction into two or more elements. To call small rod-like L-elements bacilli, as Dienes and Smith et al. have done, is misleading; structure, not size and shape, is the crux of the problem; the structure is that of an L-form; size and shape are dependent on the physical conditions of the environment. However the evidence produced from living material (Dienes \& Smith, 1944), by the electron microscope (Smith et al. 1948), and, in this paper, from stained preparations, leaves no doubt that true bacteria (A-forms) can develop from L-forms. Thus the circle is complete: A-forms produce $\mathbf{L}$-forms by the fusion of special elements, and the $\mathbf{L}$-forms can produce $\mathbf{A}$-forms.

It seems as if almost all Gram-negative bacteria can go through the L-cycle, some under ordinary cultural conditions, others only when affected by abnormal conditions; these include temperature changes, appropriate concentrations of sodium chloride, or lithium chloride, and penicillin in sublethal concentrations. In 1942 I expressed the opinion that the large 'salt forms' differed from typical L-forms such as those of Streptobacillus moniliformis, but my recent observations showed that the 'bodies' were always produced in the same way and therefore must be regarded as L-forms. Finally, the evidence is now so conclusive that A- and L-forms are two distinct phases of the same organism that my symbiont theory is untenable. 
I should like to thank Mr L. J. Hale and Miss Jacqueline Schoppig for valuable technical assistance and Dr S. T. Cowan for his help with the manuscript.

\section{REFERENCES}

Boivin, A. (1948). Notions recente sur la constitution et sur la biologie des bactéries. Revue Médicale de Liége, 3, 237.

Boivin, A., Tulasne, R., Vendrely, R. \& Minck, R. (1947). Le noyau des bactéries. Cytologie et cytochemie des bactéries normales et des bactéries traitées par la penicilline. Extrait des Archives des Sciences physiologiques, tome 1, 307.

Braun, H. \& Yalim, F. (1948). Zur Kenntnis der Chromatinkörperchen der Bakterien (Ein Beitrag zur Wirkungsweise antibakterieller Substanzen). Istanbul Seriryate yel: xxx, No. 1-Eylui 1948 (Ayri baski).

Dienes, L. (1943). Reproduction of bacteria from the large bodies of Streptobacillus moniliformis. Proc. Soc. exp. Biol. 53, 84.

Dienes, L. (1947). The morphology of the $\mathrm{L} 1$ of Klieneberger and its relationship to Streptobacillus moniliformis. J. Bact. 54, 231.

Dienes, L. (1948a). The isolation of L-type culture from Bacteroides with the aid of penicillin and their reversion into the usual bacilli. J. Bact. 56, 445.

Dienes, L. (1948b). Isolation of L-type colonies from typhoid bacilli with the aid of penicillin. Proc. Soc. exp. Biol. 68, 589.

DienEs, L. \& SMith, W. E. (1944). The significance of pleomorphism in Bacteroides strains. J. Bact. 48, 125.

Gardner, A. D. (1940). Morphological effects of penicillin on bacteria. Nature, Lond., 146, 837.

KLIENEBERGER, E. (1935). The natural occurrence of pleuropneumonia-like organisms in apparent symbiosis with Streptobacillus moniliformis and other bacteria. J. path. Bact. 40, 93.

KLIENEBERGER, E. (1942). Some new observations bearing on the nature of the pleuropneumonia-like organisms known as L 1 associated with Streptobacillus moniliformis. J. Hyg., Camb., 42, 485.

Klieneberger-Nobex, E. (1945). Changes in the nuclear structure of bacteria, particularly during spore formation. J. Hyg., Camb., 44, 99.

KLIENEBERGER-NoBEL, E. (1947). Isolation and maintenance of an L 1-like culture from Fusiformis necrophorus (syn. Bacterium funduliforme, Bacteroides funduliformis). J. Hyg., Camb., 45, 489.

Klieneberger-Nobel, E. \& Smiles, J. (1942). Some observations on the developmental cycle of the organisms of bovine pleuropneumonia and related organism: J. Hyg., Camb., 42, 110.

KNAYSI, G. \& BAKER, R. F. (1947). Demonstration, with the electron microscope, of a nucleus in Bacillus mycoides grown in a nitrogen-free medium. J. Bact. 53, 539.

Ørskov, J. (1947). Some observations on aberrant bacteria morphology. Acta path. microbiol. scand. 24, 198.

Partridge, S. M. \& Kiteneberger, E. (1941). Isolation of cholestrol from the oily droplets in association with the L 1 organism separated from Streptobacillus moniliformis. J. Path. Bact. 52, 219.

Robinow, C. F. (1944). Cytological observations on Bact. coli, Proteus vulgaris and various aerobic spore-forming bacteria, with special reference to the nuclear structures. J. Hyg., Camb., 43, 413.

RoBinow, C. F. (1945). Nuclear apparatus and cell structure of rod-shaped bacteria. Addendum in R. J. Dubos, The Bacterial Cell, in its relation to Problems of virulence, immunity and chemotherapy. Cambridge, Mass., U.S.A.: Harvard University Press. 
Smith, W. E. (1944). Observations indicating a sexual mode of reproduction in a common bacterium (Bacteroides funduliformis). J. Bact. 47, 417. Abstract of paper read to Soc. Amer. Bacteriologists.

Smith, W. E., Hri.Lier, J. \& Mudd, S. (1948). Electron micrograph studies of two strains of pleuropneumonia-like (L) organisms of human derivation. J. Bact. 56,589 .

Smith, W. E., Mudd, S. \& Hillier, J. (1948). L-type variation and bacterial reproduction by large bodies as seen in electron micrographic studies of Bacteroides funduliformis. J. Bact. 56, 603.

Tatum, E. L. \& Lederberg, J. (1947). Gene recombination in the bacterium Escherichia coli. J. Bact. 53, 673.

Tulasne, R. \& Vendrely, R. (1944). Demonstration of bacterial nuclei with ribonuclease. Nature, Lond., 160, 225.

\section{EXPLANATION OF PLATES}

(Magnification $\times 3000$ )

Plate 1

Fig. 1. Fusiformis necrophorus ' 132 ', $3 \mathrm{hr} .36^{\circ}$, osmic acid, ribonuclease, Giemsa (boiled blood medium plus serum was used for ' 132 ' throughout).

Fig. 2. F. necrophorus, ' 132 ', $5 \frac{1}{2}$ hr. $36^{\circ}$, osmic acid, hydrochloric acid, Giemsa.

Figs. $3 a$ and $b . F$. necrophorus, ' 132 ', $5 \frac{1}{2}$ hr. $36^{\circ}$, osmic acid, hydrochloric acid, Giemsa.

Figs. 4 and 5. F. necrophorus, ' 132 ', $7 \mathrm{hr}$. $36^{\circ}$, osmic acid, ribonuclease, Giemsa.

Fig. 6. F. necrophorus, ' 132 ', $5 \frac{1}{2}$ hr. $36^{\circ}$, osmic acid, hydrochloric acid, Giemsa.

Fig. 7. F. necrophorus, $5 \frac{1}{2} \mathrm{hr} .36^{\circ}$, osmic acid, hydrochlorie acid, Giemsa.

Figs. 8 and 9. F. necrophorus, ' 132 ', 71 hr. $36^{\circ}$, osmic acid, hydrochloric acid, Giemsa.

Fig. 10. F. necrophorus, ' 132 ', $7 \frac{1}{2}$ hr. $36^{\circ}$, osmic acid, hydrochloric acid, Giemsa.

Plate 2

Fig. 11. F. necrophorus, ' 132 ', $7 \mathrm{hr} .36^{\circ}$, osmic acid, ribonuclease, Giemsa.

Fig. 12. F. necrophorus, ' 132 ', $24 \mathrm{hr} .36^{\circ}$, osmic acid, hydrochloric acid, Giemsa.

Fig. 13. Bact. coli, '204', meat infusion peptone agar, $5 \mathrm{hr} .36^{\circ}$, osmic acid, Giemsa.

Fig. 14. Bact. coli, ' 204 ', meat infusion peptone agar, $5 \mathrm{hr}$. $36^{\circ}$, osmic acid, hydrochloric acid, Giemsa.

Fig. 15. Pasteurella pestis, '144', boiled blood medium, $2 \%$ sodium chloride, overnight room temperature, $5 \mathrm{hr} .36^{\circ}$, osmic acid, hydrochloric acid, Giemsa.

Fig. 16. Past. pestis, ordinary nutrient agar, $6 \mathrm{hr}$. $36^{\circ}$, edge of micro-culture, osmic acid, ribonuclease, Giemsa.

Fig. 17. Past. pestis, '144', boiled blood medium, $2 \%$ sodium chloride, overnight room temperature, $5 \mathrm{hr} .36^{\circ}$, osmic acid, hydrochloric acid, Giemsa.

Fig. 18. Past. pestis, ' 144 ', ordinary nutrient agar, $6 \mathrm{hr} .36^{\circ}, 1 \%$ sodium-chloride, osmic acid, ribonuclease, Giemsa.

Fig. 19. Past. pestis, ' 144 ', ordinary nutrient agar, $1 \%$ sodium-chloride, overnight room temperature, $1 \frac{1}{2} \mathrm{hr} .36^{\circ}$, osmic acid, hydrochloric acid, Giemsa.

Fig. 20. Past. pestis, ' 144 ', ordinary nutrient agar, overnight room temperature, $2 \mathrm{hr} .36^{\circ}$, $1.5 \%$ sodium-chloride, osmic acid, ribonuclease, Giemsa.

\section{Plate 3}

Fig. 21. Bact. coli mutabile, ' 2495 ', nutrient agar plus $0.1 \%$ lithium chloride, $6 \frac{1}{2} \mathrm{hr} .36^{\circ}$, osmic acid, hydrochloric acid, Giemsa.

Fig. 22. Bact. coli mutabile, ' 2495 ', nutrient agar plus $0 \cdot 1 \%$ lithium chloride, 9 hr. $36^{\circ}$, osmic acid, hydrochloric acid, Giemsa. 
Journal of General Microbiology, Vol. 3, No. 3
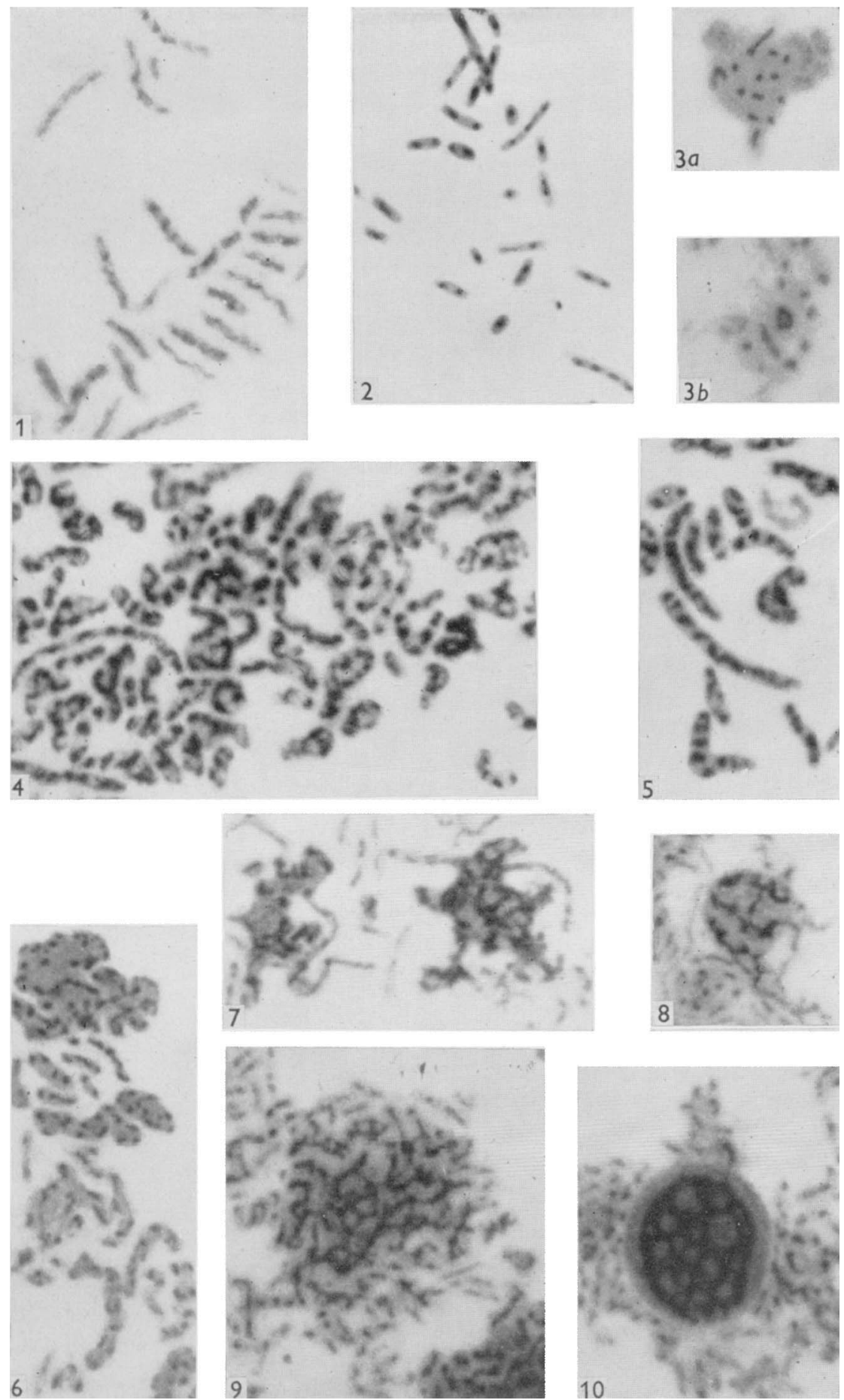

ligss, 1-10

E. Kliteneberger-Nobei- Origin of L-forms. Plate 1 
Journal of General Microbiology, Vol. 3, No. 3
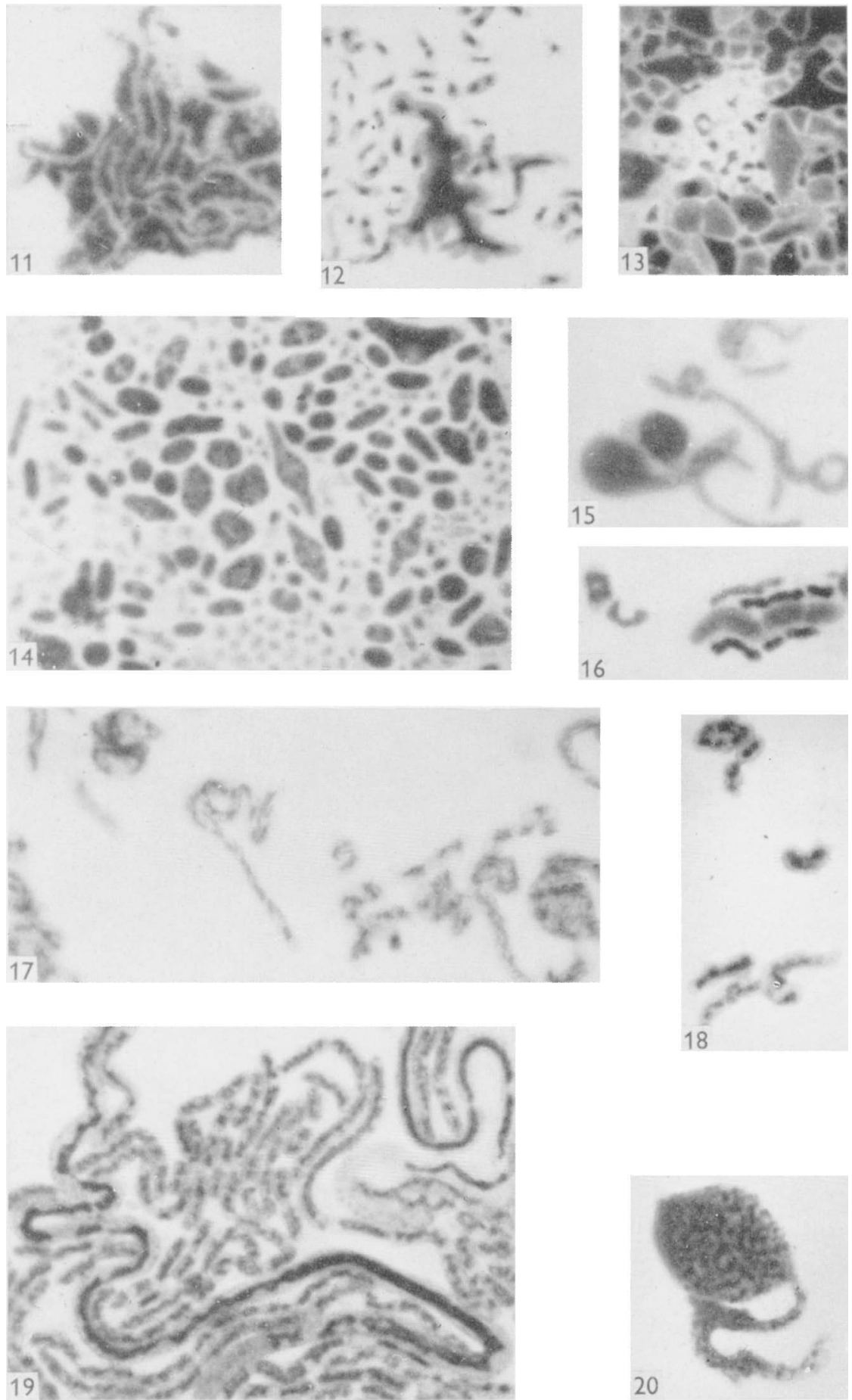

Figs. 11-20

E. Khiendierger-Nobli--Origin of L-forms. Plate 2 
Journal of General Microbiology, Vol. 3, No. 3
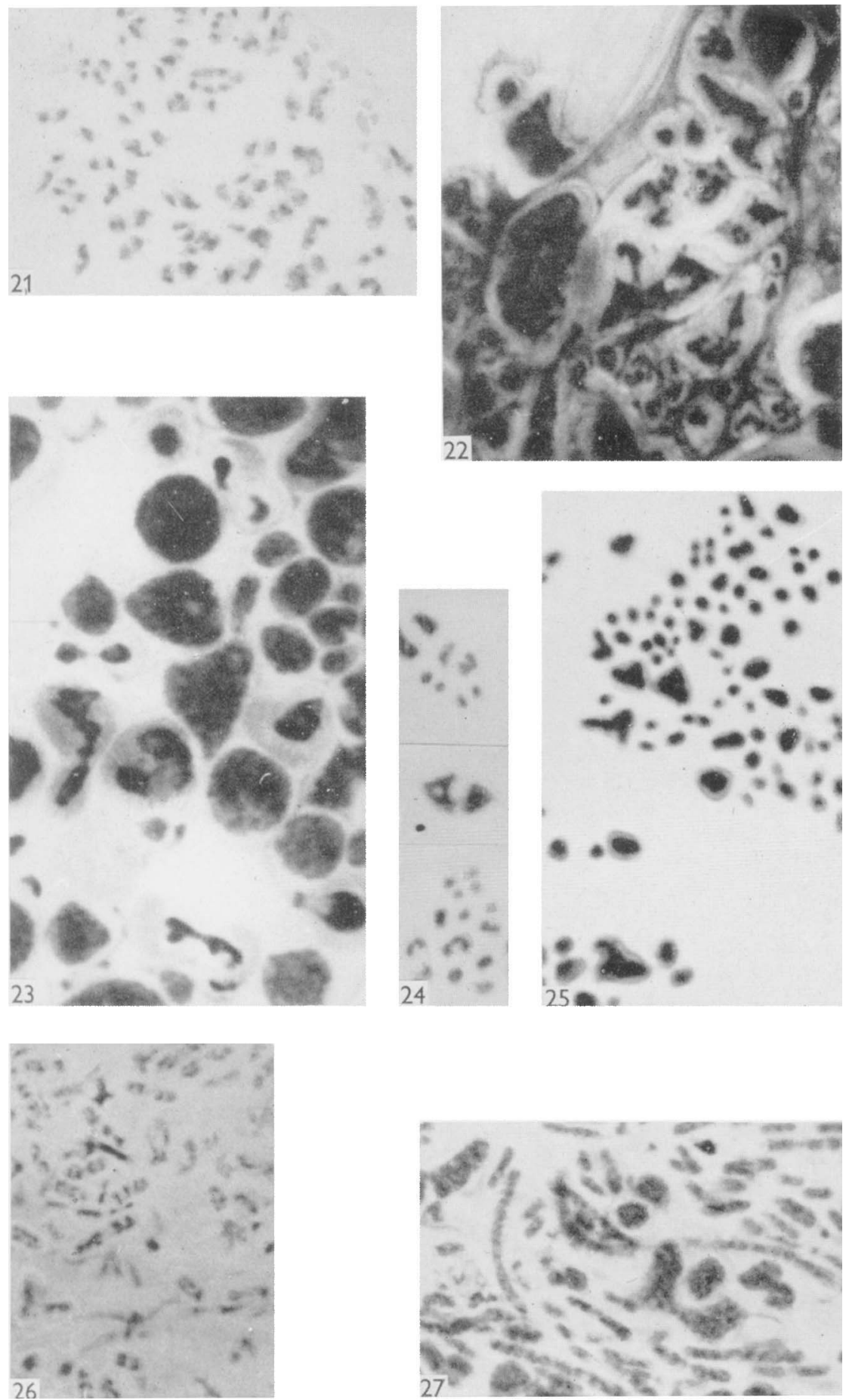

Figs. 21-27

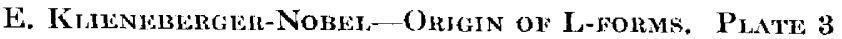


Journal of General Microbiology, Vol. 3, No. 3
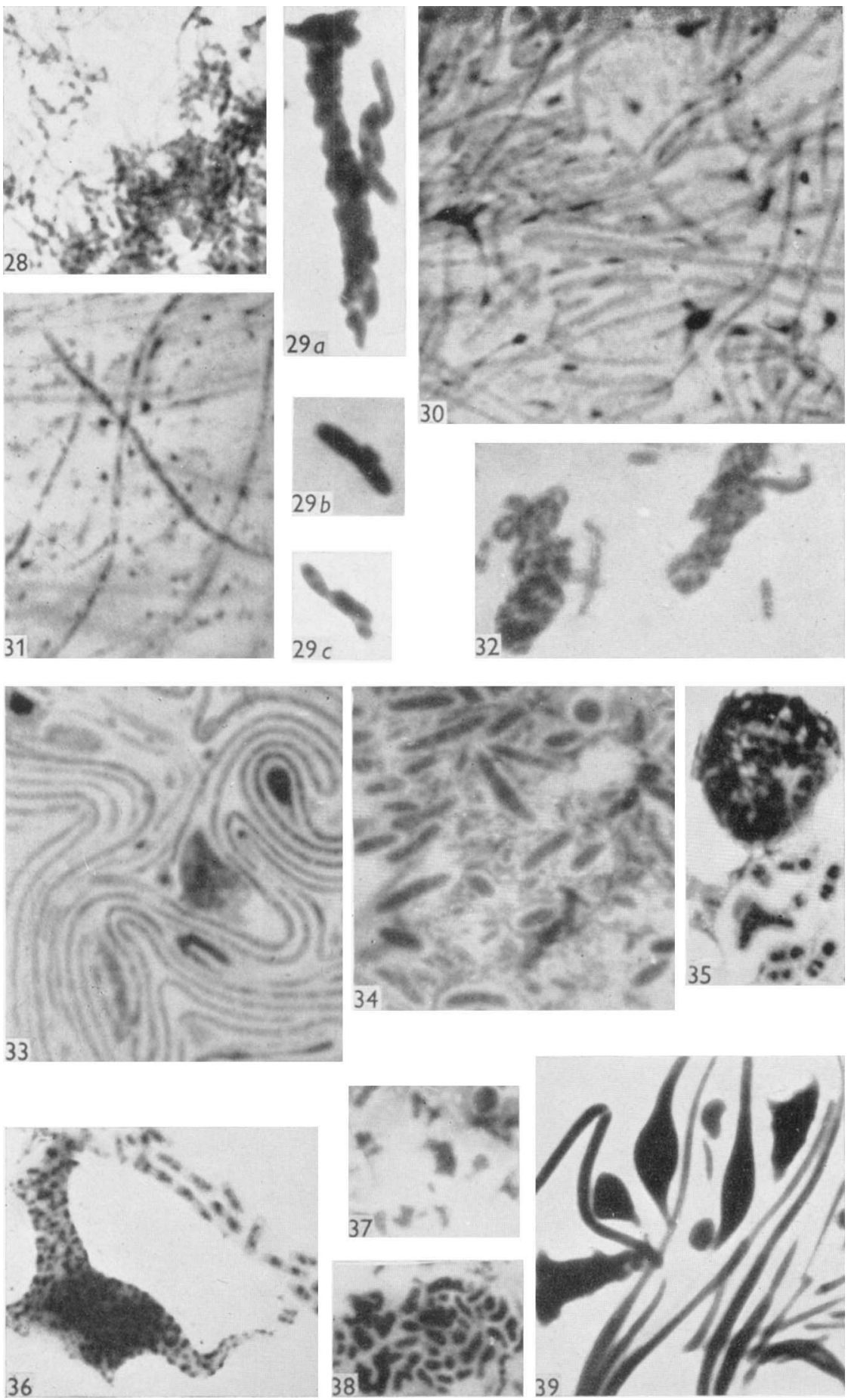

Figs. 28-39

E. Kineneblirger-Noblit-Origin of Ia-forms. Plate 4 
Fig. 23. Bact. coli mutabile ' 2495 ', nutrient agar plus $0 \cdot 1 \%$ lithium chloride, $8 \mathrm{hr}$. $36^{\circ}$, osmic acid, hydrochloric acid, Giemsa.

Fig. 24. Bact. coli mutabile ' 2495 ', nutrient agar plus $0.2 \%$ lithium chloride, overnight room temperature, $6 \mathrm{hr} .36^{\circ}$, osmic acid, hydrochloric acid, Giemsa.

Fig. 25. Bact. coli mutabile ' 2495 ', nutrient agar plus $0 \cdot 1 \%$ lithium chloride, 9 hr. $36^{\circ}$, osmic acid, hydrochloric acid, Giemsa.

Fig. 26. Proteus sp., meat infusion peptone agar with horse serum, $3 \mathrm{hr}$. incubation, then cold room for 3 days, reincubated 1 hr., osmic acid, hydrochloric acid, Giemsa.

Fig. 27. Proteus sp., swarming edge, 4 days cold room, reincubated for $2 \mathrm{hr}$, osmic acid, hydrochloric acid, Giesma.

\section{Plate 4}

Fig. 28. Salmonella paratyphi-B, ' 802 ', meat infusion peptone agar, 20 units of penicillin $/ \mathrm{ml}$. medium, $4 \mathrm{hr} . \mathbf{3 6}^{\circ}$, osmic acid, hydrochloric acid, Giemsa.

Fig. $29 a, b$ and $c$. Bact. coli mutabile ' 2495 ', nutrient agar, 40 units of penicillin $/ \mathrm{ml}$. medium, $2 \mathrm{hr} .36^{\circ}$, osmic acid, hydrochloric acid, Giemsa.

Fig. 30. Salmonella paratyphi-B ' 802 ', meat infusion peptone agar, 20 units penicillin/ml. medium, $4 \frac{1}{2} \mathrm{hr} .36^{\circ}$, osmic acid, hydrochloric acid, Giemsa.

Fig. 31. S. paratyphi-B, ' 802 ', meat infusion peptone agar, 20 units penicillin/ml. medium, $5 \mathrm{hr}$. at $36^{\circ}$, osmic acid, hydrochloric acid, Giemsa.

Fig. 32. S. paratyphi-B, ' 801 ', meat infusion peptone agar, 40 units penicillin $/ \mathrm{ml}$. medium, $3 \frac{1}{2}$ hr. at $36^{\circ}$, osmic acid, hydrochloric acid, Giemsa.

Fig. 33. S. paratyphi-B, ' 802 ', meat infusion peptone agar, 20 units penicillin/ml. medium, $6 \mathrm{hr} .36^{\circ}$, osmic acid, hydrochloric acid, Giemsa.

Fig. 34. Proteus sp., boiled blood medium, 800 units penicillin/ml. medium, osmic acid, hydrochloric acid, Giemsa.

Fig. 35. Bact. coli, '204', boiled blood agar, 400 units penicillin $/ \mathrm{ml}$. medium, during the day at $36^{\circ}$ and then room temperature overnight, osmic acid, hydrochloric acid, Giemsa.

Fig. 36. Proteus sp., nutrient agar, 400 units penicillin $/ \mathrm{ml}$. medium, $18 \mathrm{hr} .36^{\circ}$, osmic acid, hydrochloric acid, Giemsa.

Fig. 37. Bact. coli, '204', nutrient agar, 800 units penicillin $/ \mathrm{ml}$. medium, $2-3 \mathrm{hr}$. $36^{\circ}$, osmic acid, Giemsa.

Fig. 38. Proteus sp., nutrient agar, 400 units penicillin $/ \mathrm{ml}$. medium, $18 \mathrm{hr}$. at $36^{\circ}$, osmic acid, hydrochloric acid, Giemsa.

Fig. 39. Proteus sp., nutrient agar, 400 units penicillin/ml. medium, $3 \frac{3}{4} \mathrm{hr} .36^{\circ}$, osmic acid, hydrochloric acid. Giemsa.

(Received 17 February 1949) 